\title{
MICROWAVE ION SOURCE AND BEAM INJECTION FOR AN ACCELERATOR-DRIVEN NEUTRON SOURCE *
}

\author{
J. H. Vainionpaa, R. Gough, M. Hoff, J. W. Kwan, B. A. Ludewigt, M. J. Regis, \\ J. G. Wallig, R. Wells, LBNL, Berkeley, California
}

\section{Abstract}

An over-dense microwave driven ion source capable of producing deuterium (or hydrogen) beams at 100$200 \mathrm{~mA} / \mathrm{cm}^{2}$ and with atomic fraction $>90 \%$ was designed and tested with an electrostatic low energy beam transport section (LEBT). This ion source was incorporated into the design of an Accelerator Driven Neutron Source (ADNS). The other key components in the ADNS include a $6 \mathrm{MeV}$ RFQ accelerator, a beam bending and scanning system, and a deuterium gas target. In this design a $40 \mathrm{~mA} \mathrm{D} \mathrm{D}^{+}$beam is produced from a $6 \mathrm{~mm}$ diameter aperture using a $60 \mathrm{kV}$ extraction voltage. The LEBT section consists of 5 electrodes arranged to form 2 Einzel lenses that focus the beam into the RFQ entrance. To create the ECR condition, 2 induction coils are used to create $\approx 875$ Gauss on axis inside the source chamber. To prevent $\mathrm{HV}$ breakdown in the LEBT a magnetic field clamp is necessary to minimize the field in this region. Matching of the microwave power from the waveguide to the plasma is done by an autotuner. We observed significant improvement of the beam quality after installing a boron nitride liner inside the ion source. The measured emittance data are compared with PBGUNS simulations.

\section{INTRODUCTION}

An accelerator-driven neutron source (ADNS) for scanning cargo containers to detect shielded nuclear material [1] was designed at Lawrence Berkeley National Laboratory (LBNL). The key components of the ADNS include a high current $\mathrm{D}^{+}$ion source, a low energy beam transport (LEBT) section, a RFQ accelerator, beam bending and scanning magnets, and a deuterium gas target. The system can produce neutrons with energy up to $8.5 \mathrm{MeV}$ in a forward directed flux of up to $2.0 \mathrm{E} 7 \mathrm{n} / \mathrm{cm}^{2} / \mathrm{s}$ at $2.5 \mathrm{~m}$ distance from the target. [2] A schematic diagram of the ADNS is shown in Fig.1. Topic of this paper is the ion source and LEBT section shown in Fiq.2. [3-4]. Our design goal is to have a time-averaged beam current of $1.5 \mathrm{~mA}$, at $\approx 5 \%$ duty factor. Taking beam loss into consideration, the required peak current from the ion source is $\approx 40$ $\mathrm{mA} \mathrm{D}{ }^{+}$ions with a pulse length of $\approx 0.3 \mathrm{~ms}$ and 180 $\mathrm{Hz}$ repetition rate.
For this application, we have chosen to use the 2.45 $\mathrm{GHz}$ microwave ion source because of its capability

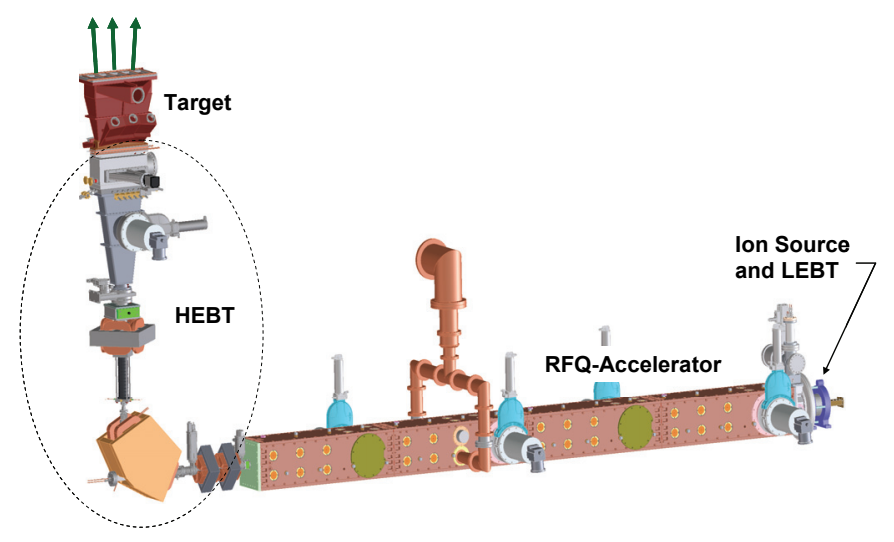

Figure 1: ADNS system schematics.

In producing high ion current density, and low min order to minimize neutron generation at the test stand, the ion source and LEBT tests were made using Hydrogen gas instead of Deuterium. Thus the required peak current scales to $\approx 57 \mathrm{~mA}$ of $\mathrm{H}^{+}$for a matched perveance.

\section{ION SOURCE}

Microwave source was selected due to it's high power efficiency, and reliability. The design of the ion source is presented in Fig. 2. The $2.45 \mathrm{GHz}$ microwave is generated using magnetron and transmitted to the ion source using a wave-guide. RF is impedance matched to ion source using an auto-tuner. A pair of solenoids is used to generate an axial magnetic field required to form an ECR condition.

It is necessary to shield the LEBT from the stray magnetic field because it affects the beam optics and also causes high voltage break down problems. This was done by installing a magnetic steel plate at the source exit. Unfortunately the magnetic field clamp at the present location has an adverse effect to the beam current and species. In the source we used boron nitride (BN) lining to increase the atomic fraction and extracted current density. [1,7,8] The source has optimum operation when the gas flow was $\sim 1.5 \mathrm{sccm}$ equivalent of $\sim 0.15 \mathrm{~Pa}$. 


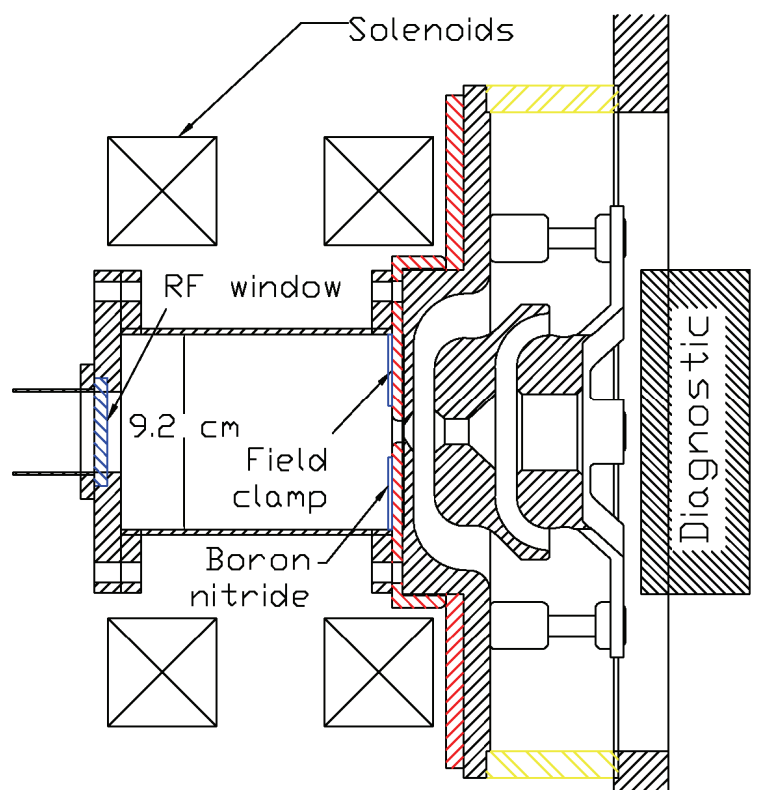

Figure 2: Schematic of the ion source and the test extraction. Diagnostic can be Faraday cup to measure the current, Wien filter to measure the ion species or Pepperpot to measure emittance.

\section{Ion source design}

There is a magnetic field clamps on front flange of the source to prevent the B-field to penetrate to the extraction area. It has been shown [6] that best $\mathrm{D}^{+}$or $\mathrm{H}^{+}$species and currents are achieved if the magnetic fields are uniform through out the source. We noticed that when the field clamp is used the deformation of the magnetic fields affects the coupling of RF power to plasma reducing the source performance. Figures 3 and 4 show the effect of magnetic clamps to the magnetic fields in the source and the LEBT and the ion current yield. About a factor of two more power is required to gain the same extracted beam current densities with field clamp than with out.

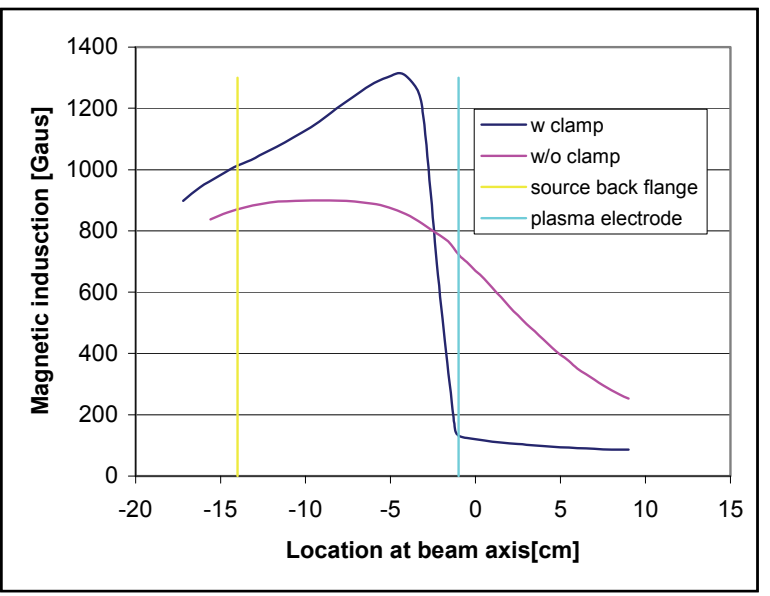

Figure 3: Magnetic fields on the central axis of the source. Measurements are done using $106 \mathrm{~A}$ induction current.

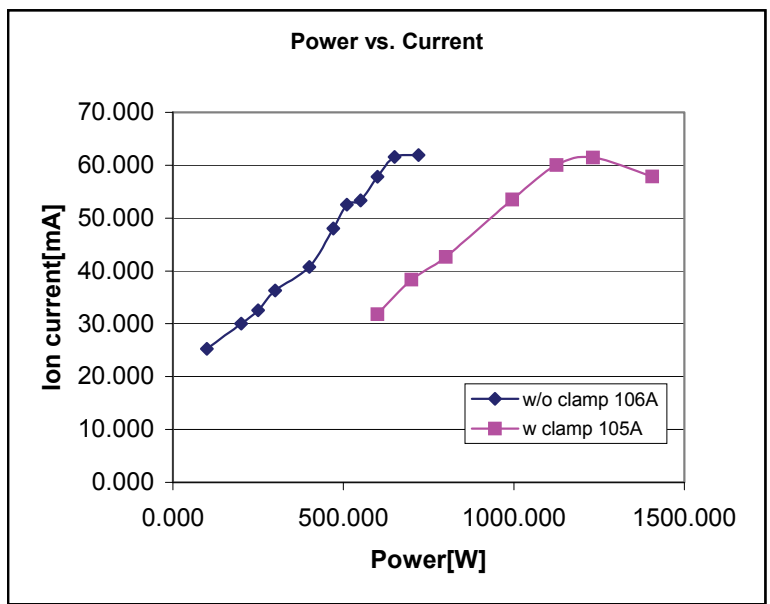

Figure 4: Ion current as function of RF power for setup with and without field clamp. In both cases, extraction voltage was $60 \mathrm{kV}$, gas flow $1.5 \mathrm{sccm}$ and magnetic induction currents between $105 \mathrm{~A}$ and $106 \mathrm{~A}$.

For the ion species, a drop from $\sim 90 \%$ to $\sim 50 \%$ on the $\mathrm{H}^{+}$fraction was detected when the field clamp was added. We suspect that the stronger field caused by the clamp near the $\mathrm{BN}$ lining was shielding the $\mathrm{BN}$ from the plasma and thus reduced the effect of $\mathrm{BN}$ in producing $\mathrm{H}^{+}$ions.

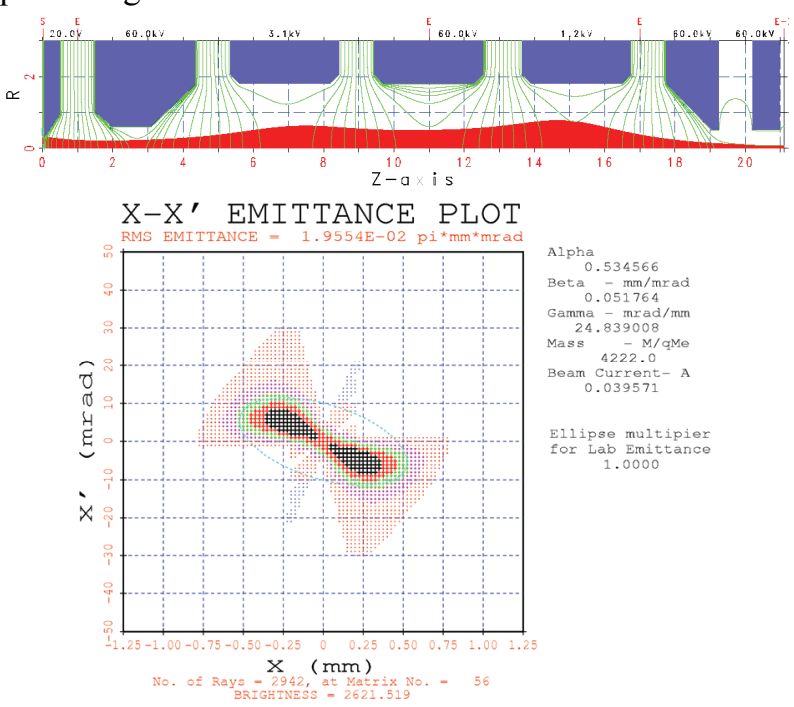

Figure 5: Trajectory plot and emittance at the entrance of the RFQ for the designed LEBT

\section{LEBT}

Preliminary design of the LEBT was done using PBGUNS simulation codes [9]. In our design, the LEBT consists of an extraction gap and two Einzel lens, in total 6 electrodes, as shown in Fig. 5. The two Einzel lenses give good control over the twiss parameters at the entrance of the RFQ. The designed 
LEBT can deliver the required $40 \mathrm{~mA}$ of $\mathrm{D}^{+}$current to the entrance of the RFQ with an emittance of

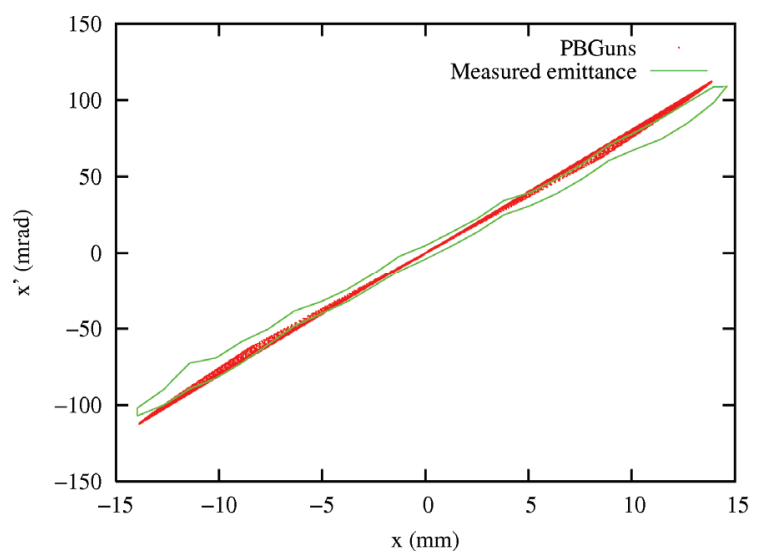

Figure 6: Graph presenting the measured emittance and simulated emittance from PBGUNS output. For the measurements the Ion current was $22 \mathrm{~mA}$, effective mass $2.4 \mathrm{amu}, \mathrm{B}$-field $100 \mathrm{G}$.

$\varepsilon_{\mathrm{n}, 1 \mathrm{RMS}}=0.0195$ pi-mrad-mm and twis parameters of $\alpha$ $=0.535, \beta=0.0518 \mathrm{~mm} / \mathrm{mrad}$ and $\gamma=24.84$ $\mathrm{mrad} / \mathrm{mm}$. These designed parameters are well inside the RFQ acceptance of $\varepsilon_{\mathrm{n}, 1 \mathrm{RMS}}=0.055 \mathrm{pi}$-mrad-mm, $\alpha=$ $1, \beta=0.07 \mathrm{~mm} / \mathrm{mrad}$ and $\gamma=28.57 \mathrm{mrad} / \mathrm{mm}$.

In order to confirm the accuracy of the simulations, we built a test extraction and compared the measured emittance results with the simulation. This test extraction consists of a triode setup as shown in Fig.2. Diagnostics was done by using Faraday cup, Wien filter or pepper pot emittance located after the last electrode.

The emittance diagnostic consists of a multi-slit screen positioned $1.2 \mathrm{~cm}$ after the last electrode followed by a kapton foil $9.8 \mathrm{~cm}$ downstream of the slit screen. Each slit width was $0.2 \mathrm{~mm}$ wide and the separation between slits was $1.27 \mathrm{~mm}$. The ion source operation parameters during the emittance measurement (Fig. 6) were at gas flow $1.5 \mathrm{sccm}, \mathrm{RF}$ power $1070 \mathrm{~W}$ and magnet coil current of $106 \mathrm{~A}$. The measured ion current was $22 \mathrm{~mA}$ and the species were $58 \% \mathrm{H}^{+}, 21 \% \mathrm{H}_{2}^{+}, 10 \% \mathrm{H}_{3}{ }^{+}$and $10 \%$ of impurities (mass $\sim 17$ and $\sim 25$ ). Giving us an effective mass $\mathrm{m}_{\text {eff }}$ $\approx 2.4 \mathrm{amu}$.

$m_{\text {eff }}=\left(f_{1} \sqrt{m_{1}}+f_{2} \sqrt{m_{2}}+f_{3} \sqrt{m_{3}}+\ldots\right)^{2}$

Here $f_{n}$ and $m_{n}$ are fractions from total ion current and mass of species $n$.

Figure 6 shows measured emittance obtained from the emittance measurement and $\mathrm{x}-\mathrm{x}$ ' phase plot of the PBGUNS simulation with the same current and species as in the measured emittance.
In addition to beam current and species the beam spot and divergence are affected by LEBT geometry, electrode voltages and magnetic field in the LEBT. Error in the definition of any of these variables on the simulation might cause the minor disparity of the beam spot size and divergence seen in Fig. 6. Space charge and charging of the kapton foil in the drift region behind the slit screen were not taken into account when determining the measured emittance. Within the measurement tolerances it seems that the measured and simulated emittance are in good agreement with each other.

\section{CONCLUSION}

We have produced the required current and species for the ADNS application when in absence of a magnetic field clamp [1]. We observed considerable reduction on the extracted ion currents and $\mathrm{H}^{+}$species when the field clamp was placed on the plasma electrode. This problem can be overcome by either optimizing the position of the field clamp (e.g. at the back of the extraction electrode) or by using permanent magnets (PM) to generate the required magnetic fields. PM sources have been shown to work well [10] and stray fields from permanent magnets are not as far reaching as fields caused by the field coils.

The measured emittance agrees with the simulated emittance thus confirming the validity of the PBGUNS calculation and its usage in designing the LEBT.

\section{REFERENCES}

[1] D. Slaughter et al., IEEE Sensors Journal, Vol. 5, No. 4 (2005), 560-564.

[2] B. A. Ludewigt, D. L. Bleuel, J. W. Kwan: HighYield Neutron Source for Cargo Container Screening, IEEE Nuclear Science Symposium Oct. 29 to Nov. 4, 2006, San Diego, CA.

[3] J. W. Kwan, R. A.Gough, B.A. Ludewigt, M. Regis, R. P. Wells, J. H. Vainionpaa "A $2.45 \mathrm{GHz}$ high current ion source for neutron production" 17th international workshop on ECR ion sources and their applications 2006, Lanzhou ,China.

[4] J. W. Kwan, R. Gough, M. D. Hoff,: "The Design of a $6 \mathrm{MeV}$ Deuteron RFQ Accelerator as a Low Energy Neutron Source", 18th Meeting of the International Collaboration on Advanced Neutron Sources 2007.

[5] M. Tanaka, S. Hara, T. Hae, Rev. Sci. instrum 75 (2004) 5

[6] T. Taylor, J. F. Mouris, Nucl. Instr. and Meth. A 336 pp.1-5.

[7] J. H. Vainionpaa, T. Kalvas, S. Hahto, Rev. Sci. Instrum. 2007.(to be published)

[8] C. F. Chan, C. F. Burnell, W. S. Cooper, J. Appl. Phys 54 (1983) p. 6119. 
[9] PBGUNS version 5.04, by Jack E. Boers, Thunderbird Simulations, 2001.

[10] Z. Song, S. Peng,a_J. Yu, Rev. Sci. instrum 77 (2006) 03A305 